\title{
Hubungan Penilaian Kinerja Terhadap Hasil Belajar Biologi Materi Sistem Sirkulasi Pada Manusia Di Kelas Xi Madrasah Aliyah Negeri Wara Ambon
}

\author{
M. Faqih Seknun' ${ }^{1}$ Janaba Renngiwur ${ }^{2}$, Nurlaila Sopamena ${ }^{3}$ \\ Jurusan Pendidikan Biologi IAIN Ambon \\ Email: faqihnona@gmail.com
}

\begin{abstract}
Abstrak: Pembelajaran sebagai proses pendidikan memerlukan siasat, pendekatan, metode dan teknik yang bermacam-macam sehingga siswa dapat menguasai materi dengan baik dan mendalam. Pada proses belejar mengajar, penilaian proses terhadap hasil belajar mengajar sering diabaikan, setidaknya-tidaknya kurang mendapat perhatian dibandingkan penilaian hasil belajar. Padahal untuk mengetahui proses pembelajaran itu berhasil atau tidak, siswa aktif atau tidak harus dinilai mulai saat pembelajaran itu berlangsung. Permasalahan dalam penelitian ini adalah apakah hubungan penilaian kinerja terhadap hasil belajar dan berapa besar hubungan penilaian kinerja terhadap hasil belajar biologi materi system sirkulasi pada manusia di Kelas XI MA Negeri Wara Ambon. Penelitian ini menggunakan tipe korelasional yang bertujuan mengukur besarnya hubungan penilaian kinerja terhadap hasil belajar biologi materi sirkulasi pada manusia. Hasil penelitian menunjukkan bahwa terdapat hubungan penilaian kinerja terhadap hasil belajar biologi materi sirkulasi. Hasil tersebut diinterpretasikan nilai $r=0,67$ masuk pada ketgori sedang atau cukup yang mana menunjukkan bahwa hubungan penilaian kinerja memiliki korelasi yang sedang atau cukup. Berdasarkan koefisien determinasi, maka besarnya sumbangan kebiasaan belajar siswa yaitu $70.73 \%$. Dengan demikian, faktor lain seperti kemampuan konsep, kemampuan memahami materi serta kemampuan bertanya menentukan keberhasilan belajar hanya sekitar 29,27\%.
\end{abstract}

\section{Kata Kunci: Biologi, Penilaian Kinerja, Sirkulasi}

Abstract: Learning as an educational process require tactic, approach, method, and various techniques so students can master the material well and deep in the process of teaching and learning, the assessment of the process of teaching and learning outcomes is often ignored, less of attention compared with assessment of learning outcomes. Whereas to find out the learning process was successful or not. Active students or not must be assessed at the time learning is on. Problem in this research is whether the relationship of performance appraisal to learning outcomes and how much the relationship of performance appraisal to learning biology the material circulation system in humans at XI MA Negeri Wara Ambon. This research uses type correlational aim to measure how far the relationship of performance appraisal to learning biology the material circulation system in humans. Result of research show that the relationship of 
performance appraisal to learning biology the material circulation. The result interpretation value $r=0,67$ consist of medium category or enough. Based on the coefficient if determination, so amount of contribution students learning habit is $70.73 \%$. Therefore, another factor as concept ability, ability of understanding material and question ability determine learning success around $29,27 \%$.

\section{Key Words: Biology, Performance Assessment, Circulation}

Era globalisasi dan pasar bebas mengakibatkan manusia harus berhadapan dengan perubahan-perubahan yang tidak menentu. Salah satunya adalah perubahan yang terjadi pada system pendidikan di Indonesia, baik perubahan pada kurikulum pendidikan, media atau sarana pendidikan maupun metode pengajaran. Disisi lain, saat ini telah memasuki era Industri 4.0 di mana kecepatanlah menjadi kunci dari keberhasilan. Era ini menuntut segala hal untuk bergerak cepat dengan bantuan teknologi, sehingga penguasaan teknologi tepat guna pada berbagai aspek harus dikuasai. Saat ini, pemerintah telah meluncurkan berbagai program untuk meningkatkan mutu pendidikan dan peningkatan kegiatan belajar mengajar. Guru dan murid dapat mengakses berbagai informasi untuk meningkatkan kualitas pendidikan lewat berbagai aplikasi dan media pembelajaran. Namun untuk mengukur kualitas mereka haruslah tetap dilakukan di lembaga-lembaga formal melalui berbagai macam metode dan teknik yang relevan (Toatubun, F. A., \& Rijal, M, 2018).

Pembelajaran sebagai proses pendidikan memerlukan siasat, pendekatan, metode, dan teknik yang bermacam-macam sehingga siswa dapat menguasai materi dengan baik dan mendalam. Untuk mewujudkannya, kemampuan mendayagunakan metode atau cara mengajar sangat diperlukan untuk lebih menjamin swadaya dan swakarsa peserta didik yang sesuai dengan perkembangan ilmu pengetahuan dan teknologi. Paradigma baru pendidikan menghendaki dilakukannya inovasi yang terintegrasi dan bekesinambungan antara media pembelajaran yang digunakan maupun proses belajar mengajar. Siswa dapat meningkatkan ilmu pengetahuan mereka dengan memanfaatkan berbagai media dan guru dapat mengakses atau menggali informasi mengenai pemahaman siswa melalui pertanyaan, observasi, pemberian tugas dan tes baik pre test maupun post test. Informasi akurat tentang hasil belajar, minat dan kebutuhan siswa hanya dapat diperoleh melalui penilaian dan evaluasi yang efektif (Sere. I \& Rijal. M, 2017)

Seringkali penilaian proses terhadap hasil belajar mengajar sering diabaikan, penilaian hanya dilakukan terhadap hasil belajar. Padahal pendidikan tidak hanya melihat hasil tetapi juga proses. Untuk itu salah satu teknik atau metode yang dapat digunakan untuk menilai kualitas adalah dengan melakukan penilaian kinerja yang berorientasi pada proses yakni keaktivan siswa pada saat proses pembelajaran. Penilaian kinerja merupakan salah satu penilaian dimana guru mengamati dan membuat pertimbangan tentang 
demonstrasi siswa dalam hal kecakapan atau kompetensi dalam menghasilkan suatu produk. Fokusnya adalah untuk mengetahui seberapa kemampuan siswa dan apakah ia bisa bekerja sama dana tau lebih efektif pada masa yang akan datang, sehingga semuanya memperoleh manfaat. Penilaian berbasis kinerja ini adalah suatu usaha untuk memperoleh berbagai informasi secara berkala (Rijal. M, 2018), berkesinambungan, dan menyeluruh tentang proses dann hasil pertumbuhan serta perkembangan wawasan pengetahuan, sikap dan keterampilan siswa yang bersumber dari catatan dan dokumentasi.

Berdasarkan uraian di atas maka perlu dilakukan penelitian terkait hubungan penilaian kinerja terhadap hasil pembelajaran. Sehingga peneliti melakukan penelitian dengan judul hubungan penilaian kinerja terhadap hasil belajar biologi Materi Sistem Sirkulasi pada Manusia Di Kelas Xi Madrasah Aliyah Negeri Wara Ambon. Tujuan dari penelitian untuk mengetahui hubungan penilaian kinerja terhadap hasil belajar biologi materi system sirkulasi pada manusia di Kelas XI MA Wara Ambon.

\section{METODE PENELITIAN}

Penelitian ini menggunakan tipe korelasional yang bertujuan mengukur besarnya hubungan penilaian kinerja terhadap hasil belajar biologi materi system sirkulasi pada manusia di Kelas XI MA Wara Ambon. Pengumpulan data pada penelitian dilakukan dengan cara observasi, identifikasi prestasi belajar siswa, pelaksanaan proses pembelajaran, pencatatan perilaku kemampuan spesifik untuk menyelesaikan masaha, membuat kriteria kemampuan yang akan diukur, membuat isntrumen penilaian, melakukan test hasil belajar dan analisis hasil belajar. Teknik analisis data menggunakan analisis statistik deskriptif dan analisis statistik inferensial. Penelitian dilakukan pada siswa kelas XI MA Wara Kota Ambon.

\section{HASIL DAN PEMBAHASAN}

Penilaian kinerja dikembangkan untuk menguji kemampuan siswa dalam mendemonstrasikan pengetahuan dan keterampilannya mengenai berbagai situasi nyata dalam konteks tertentu. Ratumanan mendefinisikan penilaian kinerja sebagai koleksi informasi yang berkaitan dengan demonstrasi prestasi meliputi penampilan tugas atau himpinan tugas secara aktual, seperti eksperimen, percakapan, menulis cerita, atau mengoprasikan mesin. Ratumanan mengumukakan bahwa dalam tugas kinerja, siswa mendemonstrasikan kepada audiens, bahwa mereka telah menguasai tujuan belajar tertentu.

System sirkulasi darah pada manusia merupakan aliran system sirkulasi yang tertutup, sehingga tidak ada darah yang mengalir di luar aliran darah jika dalam keadaan normal. Sedangkan system sirkulasi terbuka adalah jika berlangsung di luar pembluh, seperti aliran getah bening. Materi terkait sirkulasi sangat penting dan cukup kompleks dalam pembelajaran biologi, untuk itu perlu pembelajaran yang ekstra agar dapat menguasai materi tersebut. System sirkulasi mempelajari tentang system peredaran darah, 
transportasi, manfaat dan fungsi, alat-alat peredaran darah yakni jantung, pericardium/epicardium, miokardium maupun endocardium, mempelajari aliran dara seperti vena dan arteri,pembuluhrambut kapiler dan mekanisme perederan itu sendiri.

Berbagai materi yang kompleks ini, perlu teknik pembelajaran yang tentunya dapat membantu siswa untuk menguasai materi tersebut dan untuk melihat hubungan penilaian kinerja terhadap hasil belajar maka digunakan instrument yakni rubrik penilaian. Hasil rubric penilaian terhadap beberapa perlakuan dapat dilihat pada grafikgrafik di bawah ini.

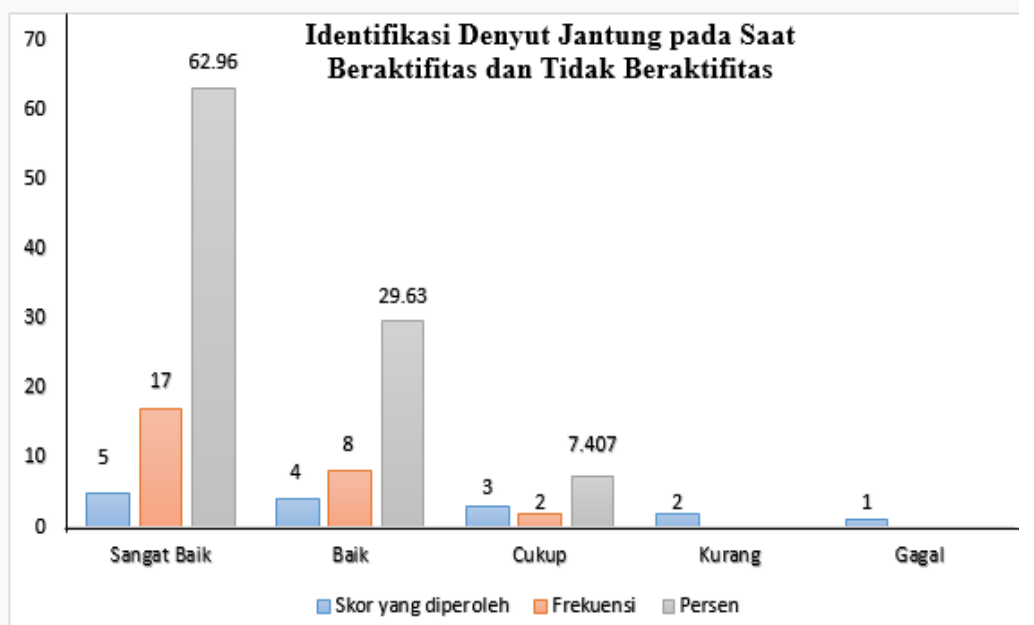

Gambar 1. Grafik Identifikasi Denyut Jantung pada Saat Beraktifitas dan Tidak Beraktifitas

Berdasarkan grafik di atas, dapat lihat bahwa kegiatan identifikasi denyut jantung pada saat beraktifitas dan tidak beraktifitas yang dilakukan oleh siswa kelas XI MA Wara dapat dideskripsikan bahwa 17 siswa (62.96\%) memperoleh kualifikasi sangat baik, 8 siswa (29.63\%) memperoleh kualifikasi baik dan 2 siswa $(7,4 \%)$ memperoleh kualifikasi cukup.

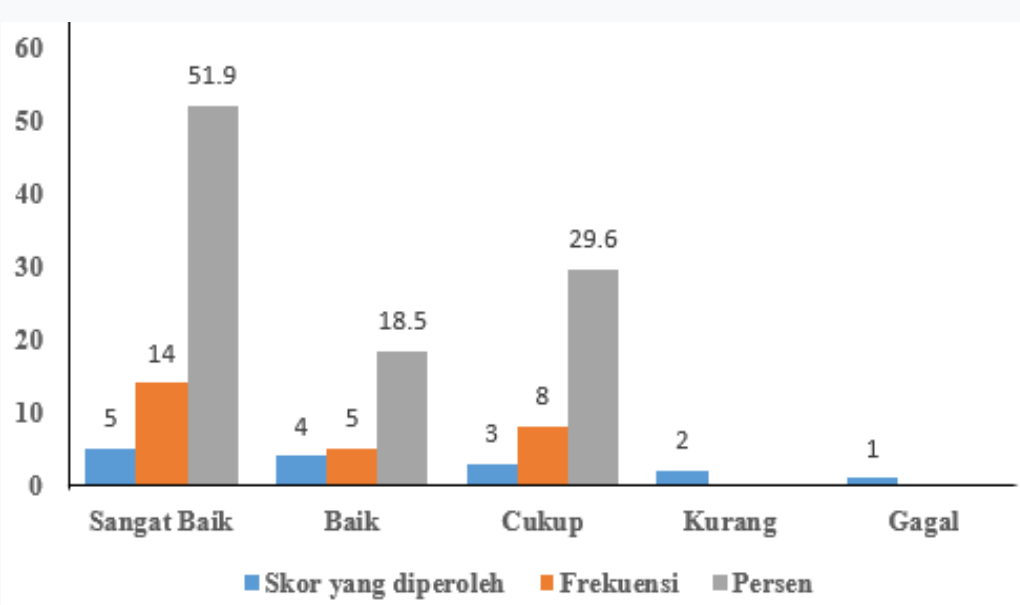

Gambar 2. Mengetahui Denyut Jantung dan Diskusi Hasil 
Berdasarkan diagram di atas, diketahui bahwa kegiatan diskusi untuk denyut jantung pada saat beraktifitas dan tidak beraktifitas yang dilakukan oleh siswa kelas XI MA Wara Ambon dapat dideskripsikan bahwa 14 siswa (51,9\%) memperoleh kualifikasi sangat baik, 5 Siswa (18.5\%) memperoleh kualifikasi baik dan 8 siswa (29.6\%) berkualifikasi cukup.

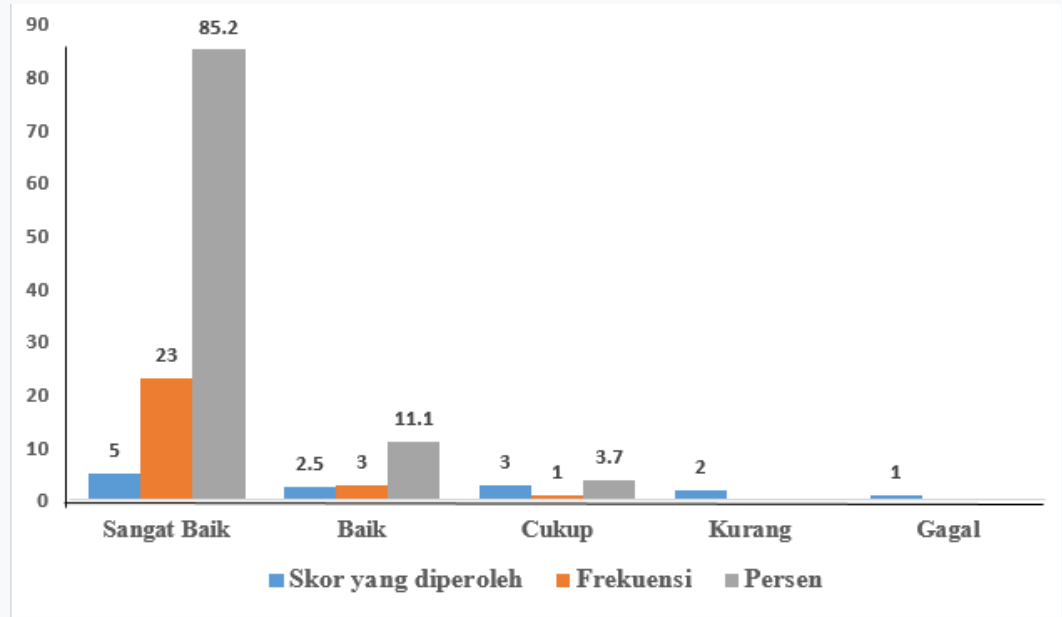

Gambar 3. Pembuatan Laporan

Berdasarkan grafik diatas, maka hasil pembuatan laporan terkait denyut jantung pada saat beraktifitas yang dilakukan oleh siswa kelas XI MA Wara dapat dideskripsikan bahwa 23 siswa (85,2\%) dengan kualifikasi sangat baik, 13 siswa (11.1\%) memperoleh kualifikasi baik dan 1 siswa (3,7\%) memperoleh kualifikasi cukup.

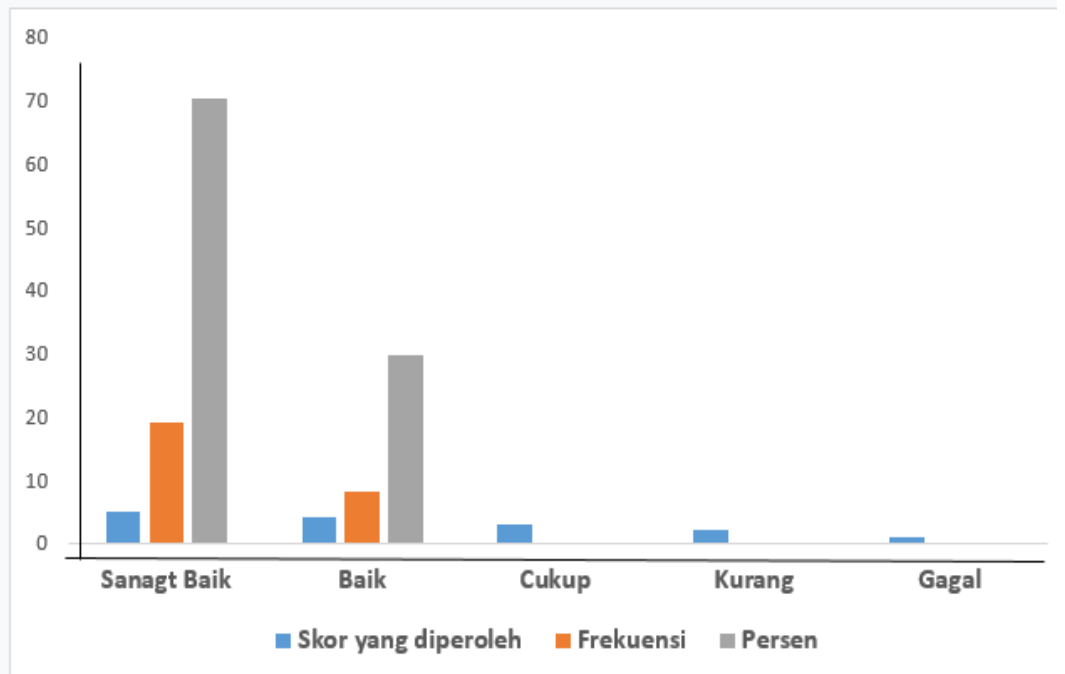

Gambar 4. Pertanggungjawaban Hasil 
Berdasarkan hasil di atas, maka pertanggung jawaban laporan tentang denyut jantung pada saat beraktifitas dan tidak beraktifitas yang dilakukan oleh siswa kelas XI MA Wara Ambon dapat dideskripsikan bahwa 19 siswa (70.4 \%) dan 8 siswa (29.6\%) memperoleh kualifikasi baik.

Berdasarkan hasil yang telah didapat, terlihat adanya hubungan penilaian kinerja terhadap hasil belajar biologi materi sistem sirkulasi pada manusia di kelas XI MA Wara Ambon, hal ini dibuktikan dengan hasil analisis Korelasi Product Moment Person. Penilaian kinerja merupakan salah satu aspek yang mempengaruhi belajar siswa tersebut pada saat proses belajar mengajar berlangsung maupun kegiatan ekstrakulikuler. Perangkat penilaian kinerja yang dilakukan melalui penelitian dalam pembelajaran dengan menggunakan task (tugas) dan rubrik penilaian kinerja agar menjadi lebih feasible (dapat dikerjakan), lengkap dan aman dilakukan. Dalam buku pedoman bagi guru perihal penilaian tingkat kelas yang dikeluarkan oleh Pusat Penilaian Pendidikan Departemen Pendidikan Nasional, disebutkan bahwa perubahan kurikulum hendaknya dipahami tidak sekedar penyesuaian subtansi materi dan format kurikulum dengan tuntutan perkembangan, tetapi merupakan pergeseran paradigm dari pendekatan pendidikan yang berorientasi masukan (Input Oriented Education) ke pendekatan pendidikan yang berorientasi hasil atau standar (Out Come Based Education). Ini berarti harus terjadi pergeseran dari pertanyaan tentang apa yang harus diajarkan (kurikulum) ke pertanyaan tentang apa yang harus terjadi ke pertanyaan tentang apa yang harus di kuasai anak (standar kompetensi) pada jenjang dan tingkat pendidikan tertentu. Dalam konteks pendidikan, satandar kompetensi sebagai acuan minimal ini diharapkan semua pihak yang terlibat didalamnya mengarahkan upaya pada pencapaian standar yang dimaksud. Seorang guru harus memiliki orientasi yang jelas tentang apa yang harus dikuasai anak didik dan memiliki kebebasan merancang proses pembelajaran untuk mencapai standar tersebut. Dengan penerapan pembelajaran berbasis penilaian kinerja maka siswa akan terlibat aktif dalam proses pembelajaran. para siswa tentunya akan merasa termotivasi dalam menunjukkan kinerja mereka, karena selama ini jarang sekali kinerja mereka dinilai.

\section{KESIMPULAN}

Hasil penelitian menunjukkan bahwa adanya hubungan penilaian kinerja terhadap hasil belajar biologi materi sIstem sirkulasi pada manusia. Berdasarkan koefisien determinasi, maka besarnya sumbangan penilaian kinerja siswa yaitu 44,26\% sedangkan $57.74 \%$ ditentukan oleh faktor lain seperti kemampuan konsep, kemampuan memahami materi serta kemampuan bertanya. Penilaian kinerja dalam proses pembelajaran harus ditingkatkan dengan bimbingan guru pengajar atau belajar berkelompok bersama teman-teman. 


\section{DAFTAR PUSTAKA}

Ahmadi Abu dan Uhbiyat Nur. (1991). IlmuPendidikan. PT Rineka Cipta. Jakarta.

Ahmadi dan Supriyono. (1991). PsikologiBelajar. PT RinekaCipta. Jakarta.

AnisaWidyaningtyas, Sukarmin, Yohanes Radiyono. 2013. Peran Lingkungan Belajar dan Kesiapan Belaja rterhadap Prestasi Belajar Fisika Siswa Kelas X Sekolah Menengah Atas Negeri1 Pati.JurnalPendidikan, (online), vol 1, No. 1, (http://www.Universitas Sebelas Maret.ac.id. Diakses April 2013)

Arikunto Suharsimi. (2006). ProsedurPenelitianSuatuPendekatanPraktik. Rineka cipta. Jakarta.

Baharudin dan EsaNurWahyuni. (2007). Teori Belajar dan Pembelajaran. Ar-Ruzz Media. Jogjakarta

Toatubun, F. A., \& Rijal, M. (2018). Professionalitas dan Mutu Pembelajaran. Uwais Inspirasi Indonesia.

Rijal, M., \& Sere, I. (2017). SARANA BERFIKIR ILMIAH. Biosel: Biology Science and Education, 6(2), 176-185.

Rijal, M. (2018). PENERAPAN MODEL PEMBELAJARAN KOOPERATIF TIPE NUMBERED HEADS TOGETHER DALAM MENINGKATKAN AKTIVITAS DAN HASIL BELAJAR COGNITIF SISWA KELAS VIII DI SMP NEGERI 14 AMBON. Jurnal BIOEDUIN: Program Studi Pendidikan Biologi, 8(2), 6-16. 